\title{
RADIO METEOR PHYSICS - A COMPARISON BETWEEN TECHNIQUES FROM 1945 to the mid-1970's
}

\section{Introduction}

The very first attempts to measure meteors with radar were undertaken by [1] in 1932, but a more committed approach to radar meteor physics began largely as a result of World War II. Towards the end of the war, radar was used in the United Kingdom to detect incoming enemy aircraft, but detection was often confused by additional targets of initially unknown origin. Studies revealed that these targets were atmospheric meteors. Initial studies of meteors by radar were intended mainly to identify and count meteors, but as time evolved, it became clear that there were also great potential scientific outcomes from such studies. One could use the drifting trails of the meteors to determine wind speeds in the upper atmosphere and potentially, and there was the possibility that more could be learned about the origins of meteors by using radar. While meteors had been well known for many years through optical observations, radar offered a new perspective.

The first post-world-war-II studies were performed by Lovell and colleagues [2], using surplus army radar equipment, and subsequently expanded to other countries including the USA, Canada and Australia. As discussed in the historical review by [2], there were a broad range of geophysical phenomena amenable to radar meteor studies. A good overview of the early history in Canada (and to a lesser extent in the USA) appears in [3]. The introduction of the International Geophysical Year in 1957 was a great success, and in the USSR, scientists from that bloc also turned their hand to meteor studies. Radars in Kazan, Ashkhabad, Kiev, Odessa, Stalinabad (Dushanbe), Tomsk, Kharkiv, Volgograd, Obninsk etc. were developed in the years following the IGY. The first radar in the USSR was developed in Kazan [4] by Kostylev in 1957, followed by one in the Ukraine at Kharkiv, led by Kashcheyev. We will return to these events shortly.

Originally meteor studies were employed to (i) help study the ionosphere [2], and (ii) determine more about the origins and nature of meteors. There was a rich array of information that could be gleaned from studies of meteors, but techniques required significant ingenuity. Early work included studies at Jodrell Bank and Manchester in the United Kingdom [5, 6], and at Stanford in the USA [7]. Work also developed in Canada [8], who was able to show that meteors were mainly particles that originally orbited the Sun, rather than being particles of interstellar origin.

\section{Early History and Techniques}

As noted, our narrative here will focus less on the history, and more on techniques, although both themes must be involved to some degree. Some of the developments discussed above took place before the advent of even modest computers, so the techniques that were required in those days were largely analytical. Yet some quite remarkable progress was made using some highly innovative methods.

In the earliest times it was largely only possible to measure amplitudes [1], but for real progress, it was necessary to measure phase and hence Doppler shift. Various authors did in time develop ways to measure phase, usually by beating the returned signal with a reference frequency and measuring the beat period and positions of the minima in the resultant beat pattern [9-11]. Initially, phases and beating were measured using CW (continuous wave) radar, but range resolution also required pulsed radar - a point that will be revisited shortly. Recording was achieved by photographing the transverse motion of electron beams produced by a cathode ray tube on horizontally moving bromide paper [12], where the transverse motions of the cathode-ray beam were driven by voltages from the receiver. Subsequent analysis was performed by reading pertinent parameters from the photographic paper-streams by eye, and hand-calculating radial velocities, phases etc. 
As an example of the type of ingenuity needed, and as alluded to above, we consider as an example work in Australia, where Robertson, Elford and Roper set about using radar is to measure winds and turbulence strengths [12]. These authors used separate transmitter and receiver antennas (multi-static system) and beat the signals received from meteor trails with the ground-wave from the transmitter to determine the phase and Doppler offset produced by the meteor drifts. Pulsed systems were eventually used, but in the earliest work, pulse modulation was supplied on top of a continuous wave [13]. In some cases separate pulsed and CW transmitters were used in unison. This allowed determination of both the meteor location and its radial velocity of motion, thereby allowing upper-level winds to be determined at $\sim 80-100 \mathrm{~km}$ altitude. These were some of the first applications of so-called "interferometry" in any field - a significant achievement! Indeed meteor studies at Jodrell Bank pre-dated astronomical studies at that site - radio astronomy actually started getting more serious when Lovell and colleagues first detected radio waves from Cygnus and Casseiopia [2] using instruments originally designed for meteor work. A more detailed explanation of the "beating" method employing ground-waves for phase determinations [12] can be found in [14], Fig. 2.9. Meteor radars were also used to make some early estimates of turbulence strengths [15 - 16], although some of the constants chosen for conversion may have been slightly in error. More details can be found in [14].

The applications of meteor radar studies evolved within several separate areas. These will be listed here, though not in any particular order of merit. The first area can be considered to be related to studies of meteor trail motions and variations, which was used to deduce information about the region of the atmosphere in which the trails formed. Another area of study related to the possibility that signals could be forward-scattered from the trails, so that the trails could be used to allow radiowave communication, even in the event of loss of an ionosphere. A third purpose was for astronomical studies. It became clear that if the speeds and directions of the meteors could be found, this could be traced backwards to allow reconstruction of the orbit of the meteors before they encountered the Earth.

Such calculations can be done by a single radar through determination of shower radiants [17], but is best done using radars with multiple receiver antennas spaced several kilometres (and even some tens of $\mathrm{km}$ ) apart. Some basic forms of this work were done in the early 1950's [8, 18]. The Harvard Radio Meteor Project in the USA was another such example, to which we will return shortly.

Application of multi-receiver stations for orbit determination became relatively common, especially with the advent of the IGY in 1957. Canada also built the Springhill Meteor Observatory around the time of the IGY [19], but of special note was the construction of several meteor radars in the USSR. The USSR was a keen contributor to the International Geophysical Year. The names of some of these sites have been noted above. Here we will concentrate on Kazan and Kharkiv.

As quoted from [20], "In the Soviet Union for a long time, beginning with the start of the Cold War in 1947, there was an initiative to catch up and overtake leading western capitalist countries, including in the domain of scientific achievements". The initiative was very successful, with the USSR launch of the first artificial satellite (Sputnik 1) on Oct 4, 1957, launch of the first living being, (Laika, a dog), into space on Sputnik 2 on Nov 3, 1957, and later, launch of the first human being to orbit the Earth, Yuri Gagarin, on 12 April 1961. Development of meteor radars were, not surprisingly, a parallel development of these efforts - after all, no-one really knew the possible impact of meteors on spacecraft. Despite the cold war, scientists from the USSR and the West did collaborate in observations of Sputnik 1[e.g. 3], who especially discussed the Canadian collaboration.

Kazan's developments have been summarized in particular by [4]. It was formally the first meteor radar in the USSR, where work started in 1957, although observers at Kharkiv did see some meteors on an ionosonde in 1954. Like the British, the first attempts at construction of meteor radar in Kazan used former military systems, which were not well suited to meteor astronomy as it used a frequency of $72 \mathrm{MHz}$. Therefore, led by K.V. Kostylev, the group set about building a dedicated meteor radar (called LARA), which went into operation in 1960. The group had a strong interest in 
determining meteor orbits, a commitment which extended well into the 1990's [ e.g. 21, 22]. Extensive discussion about this site has been presented [4]; these authors also discussed more recent developments of the site, including incorporation of a more modern facility in 2013.

Since Kazan's developments have been well discussed [4], we turn to the site at Kharkiv. The Kharkiv researchers, under the direction of B.L. Kashcheyev, also began construction in 1956 and started their observations in 1957. The first equipment developed was used throughout the period from IGY1957 to 1959, and operated at $36.9 \mathrm{MHz}$. These original studies led to the new and improved plans for meteor research, and subsequently, in 1968-1972, the Kharkiv group created for the first time in the USSR the multipurpose automated radar system MARS for research of meteors. The focus was on determination of meteor orbits. Meteors with magnitudes down to $12^{\text {th }}$ order were recorded (one of the best degrees of sensitivity that had been achieved up to the 1970's).

The specific studies at Kharkiv used multiple stations, spaced by many kilometres apart. Similar developments also took place with the Harvard Radio Meteor Project in 1957.

The Harvard project is perhaps the best documented of these early radars, and for this reason we will focus on that radar. Fig. 1 shows the flow chart for the Harvard Radio Meteor Project [23]. This was a large project to try and detect meteors by radar, modeled in part on work in the UK [24]. In turn, the Harvard design was something of a starting point for the radar in Kazan [e.g. 4], but the scientists involved then made their own adaptations to the design. The NURE radar in Kharkiv was also designed around similar principles. Another radar of similar design was one in Adelaide, Australia [25-27], although this radar only saw meteors to the 6th magnitude initially (8th magnitude after later design upgrades), while the Harvard survey went down to the 12th magnitude. The Adelaide system comprised 2 radars - a CW system and a pulsed system, both working at $27 \mathrm{MHz}$. The first was used for phase and Doppler determinations, the second for range and height determinations. For the Adelaide system, a total of 1667 meteor orbit determinations were made from Dec 1968 to June 1969, and in October 1969, with observations once per week each month.

\section{A Representative Meteor Orbit radar from the 1960's - the Harvard Radar Meteor}

The Harvard radar represents well the general ideas used for meteor research in the late 1950's and early 1960's. In this case, the antennas were also large - in the case of Harvard, the transmitter antenna produced a relatively narrow beam at an elevation of $43^{\circ}$, and an azimuthal direction $113^{\circ}$ east of true North. The half-power-half-beam width for a vertical traverse through the beam was about $18^{\circ}$, and the best width in the azimuthal direction was $28^{\circ}$ [23, Figs. 3 and 5]. The zenithal direction of $43^{\circ}$ was chosen as this is close to the region of optimal radio-meteor detections, since such a radar requires specular reflection. Meteors observed overhead must be moving horizontally for a radar to detect them by specular reflection, and such meteors are rare. These beams are relatively wide, so cannot really be used for echo location, except in a general sense. Therefore other antennas at remote sites were used to help with echo location by triangulation (since each path to different receivers will have different time delays). However, it could not be assumed that reflections from the trail were from the same point on the trail - different receiving antennas received signals from different points along the trail, and this fact allowed trail orientations to be determined. The [16] used deviations from an ideal straight line to determine turbulence strengths in the upper atmosphere. In later models, phase differences were also used to fine-tune directional details.

The transmission, reception and display circuitry for the Harvard system are shown in Fig.1: this operated in the early 1960's. Initially it was a partial system with only 3 stations, but was good enough to determine some velocity radiants and orbits of individual meteors. outlier stations could be anywhere from 5 to $40 \mathrm{~km}$ from the main transmitter base. (e.g. see [27], Fig. 1, for an example). With regard to the Harvard system, a full six station system began operating in November 1961, and a regular survey of meteor activity commenced in general for the first time in 1962. A phase comparator was also designed and built for the determination of azimuth and height of the meteor. Heights were also determined approximately from the known azimuth of the antenna. Entrance velocities were found by measurements of the Fresnel diffraction pattern at the front of the meteor 
trail, as determined by modelling [28], who further developed the early work of [29]. The Fresnel patterns at six stations were measured independently by two observers from photographic records, and the results then compared by a 7090 IBM computer. Mean data were used to determine the velocity deceleration, electron line density and radiant of the meteor. In determining the velocity, conditions were applied for the effects of diffusion in the trail, and greater precision resulted in the velocity determinations by considering these effects.

A point of some interest is the microwave links, which operated at $6 \mathrm{GHz}$. These were required to send the signal from the remote stations back to the main base. Received pulse signals were mixed with an intermediate frequency (IF) of $3 \mathrm{MHz}$. The links were also required for phase locking purposes at the remote sites, although in some cases a telephone link between the sites was used for this. In some cases, a microwave link was not used at all, but rather, dedicated cables were used to carry the remote site information back to the main base. The received pulse from the remote site was sent back via the microwave links, and included amplitude and phase. At the main site these were re-extracted at video frequencies, and compared to the signals from the other sites. The microwave links were critical to ensure that all signals had a common time-reference, and that time delays between different sites could be accurately determined. Everything was displayed on Cathode Ray Tubes, and was recorded on film - the film records were then processed manually, since modern digitization techniques were not available at the time.

The construction of radars like this was complex and expensive. The need for microwave links and telephone links, large numbers of support personnel, and large antennas, made these huge projects taking many months and even years to construct. We will return to this point later, when such a system will be compared to more modern systems which can be constructed in a few weeks, are fully self-automated, and rely on highly stable atomic clocks for timing, making the costs much lower and the efficiency much higher.

\section{Kharkiv}

For comparison purposes, we now look briefly at the meteor radar near Kharkiv. As noted, its construction was led by B.L. Kashcheyev. In 1946 Kashcheyev graduated from Kharkov Electrotechnical Institute (KHETI). He then began work at the newly formed "Fundamentals of Radio Engineering" department at KHETI, within the "Radio Engineering Faculty". From 1946 to 1950 he concurrently studied for his PhD under Abram Slutskin, head of "Fundamentals of Radio Engineering" Dept. In 1950, the Radio Engineering Faculty (including the "Fundamentals of Radio Engineering" Dept.) transferred to KhPI (Kharkiv Polytechnic Institute) and Kashcheyev moved with them. He defended his thesis in the same year.

In 1954, while still at KhPI, he and his group accidentally recorded meteors with an ionosonde, as part of a study of a solar eclipse. The meteors at the time produced extraneous reflections, which acted as a form of interference. Kascheyev subsequently visited Moscow to discuss these "interfering entities" with Fedynsky. In June 1954, after contacting Fedynsky and the international Geophysical Committee in Moscow, Kashcheyev was offered the chance to lead a scientific group in IGY 1957. In July 1954, A symposium on meteors was held in Jodrell Bank (UK) with participation of 10 countries. B. Lovell proposed to introduce radar studies into the IGY 1957 meteor research program, which fitted well with the Kkarkiv plans to study these meteors.

So Kashcheyey became the lead Ukrainian scientist in the program "International Geophysical Year of 1957 (section V 'Ionosphere and Meteors')". Kashcheyev was simultaneously appointed as head of the "Fundamentals of Radio Engineering" department (that was located within KhPI until 1971). In the year 1954 he was also awarded, along with his scientific group consisting of employees, graduate students, and students of the department "Fundamentals of Radio Engineering", funding for the construction of a suburban observational base. In 1956 this group, under Kashcheyev's guidance, began construction of an observational meteor base in the Balakliia district near the village of Olkhovatka from scratch, and was able to complete the initial instrument-complex in time to participate in the IGY. This is now known as the "Balakliyskiy Geophysical Complex". 

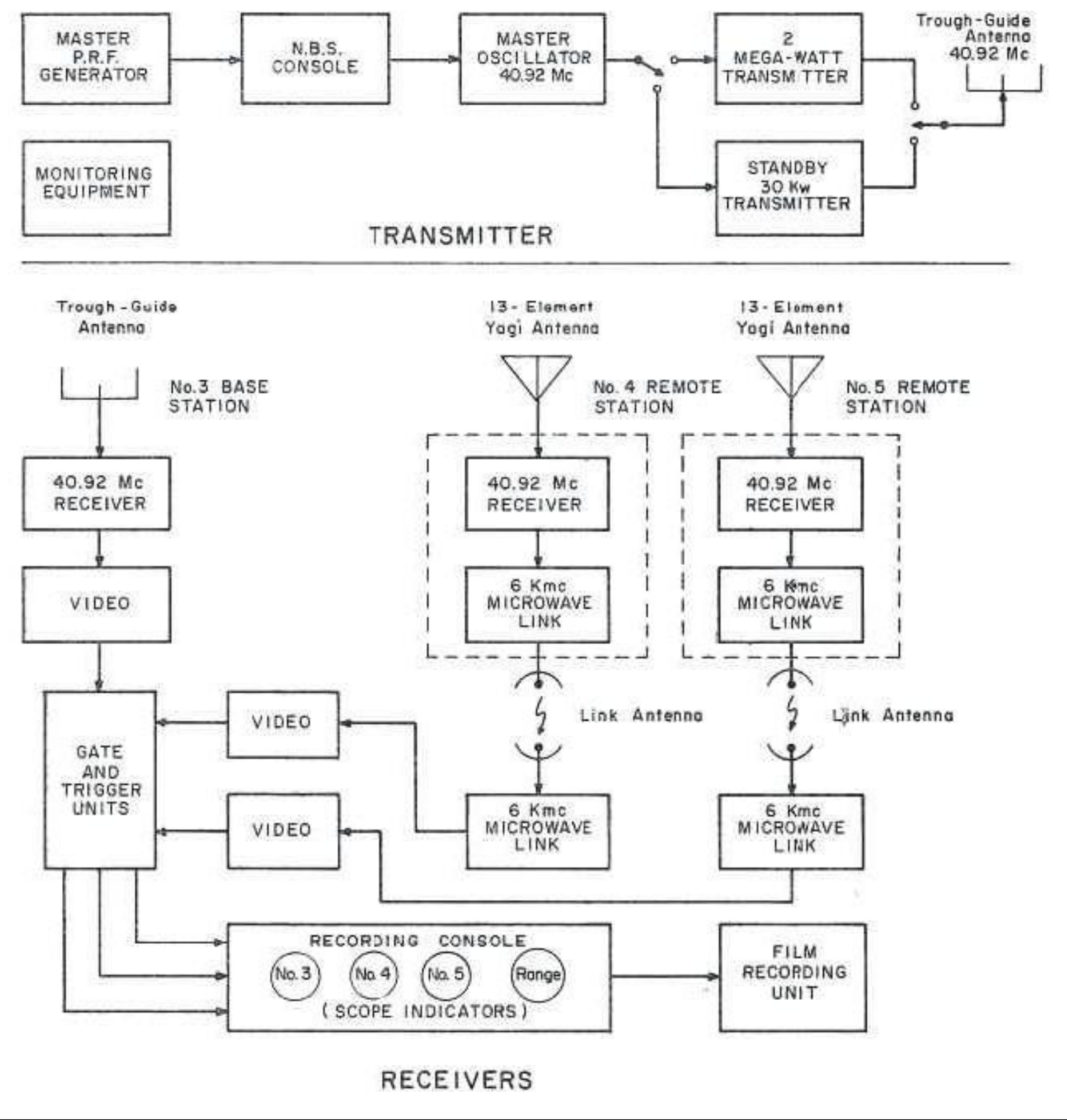

Fig. 1. Flow chart for an earlier version of the Harvard Radio Meteor Project [23]

The participation of the Kashcheyev's scientific group in the IGY 1957 program was successful. As a result, in 1958, the government allocated money for the creation of a special meteor radar laboratory called "the Problem Research Laboratory of Radio Engineering" at KhPI. After that Kharkiv radar meteor research under Kashcheyev's guidance was connected with (i) the department "Fundamentals of Radio Engineering", (ii) the Problem Research Laboratory "Radio Engineering" and (iii) the Balakliyskiy Geophysical Complex with affiliation to the institute "KhPI" until 1971. Modernization subsequently continued at the Balakliyskiy Complex for many years, throughout the 1960's and 1970's. In 1971, all structures associated with radar meteor research under Kashcheyev's guidance became affiliated with the "KHIRE" (Kharkiv Institute of Radio Electronics"). It remained as "KHIRE" until 1993, when it became "KHTURE" (Kharkiv State Technical University of Radio 
Electronics). In 2001 it became "NURE" (Kharkiv National University of Radio Electronics) and remains with this name at the time of writing of this article.

Here are more specific details about the Ukrainian system [36, 38-40] (Fig.2). As noted, the radar was located at an experimental suburban base near Balakliia. In order to participate in the IGY1957 program, Kashcheyev and his group utilized ex-military radars - referred to as "Redut" and "Pegmatit" - for the study of meteors. The Kharkiv scientists initially created a radar system having an operating frequency of $72 \mathrm{MHz}$, as recommended by the Instructions for Meteor Observations for IGY 1957. This turned out to be ineffective for meteor observations. Therefore, starting in December 1957, parallel observations were launched in Kharkiv at a frequency of $36.9 \mathrm{MHz}$ using proprietary radar systems.

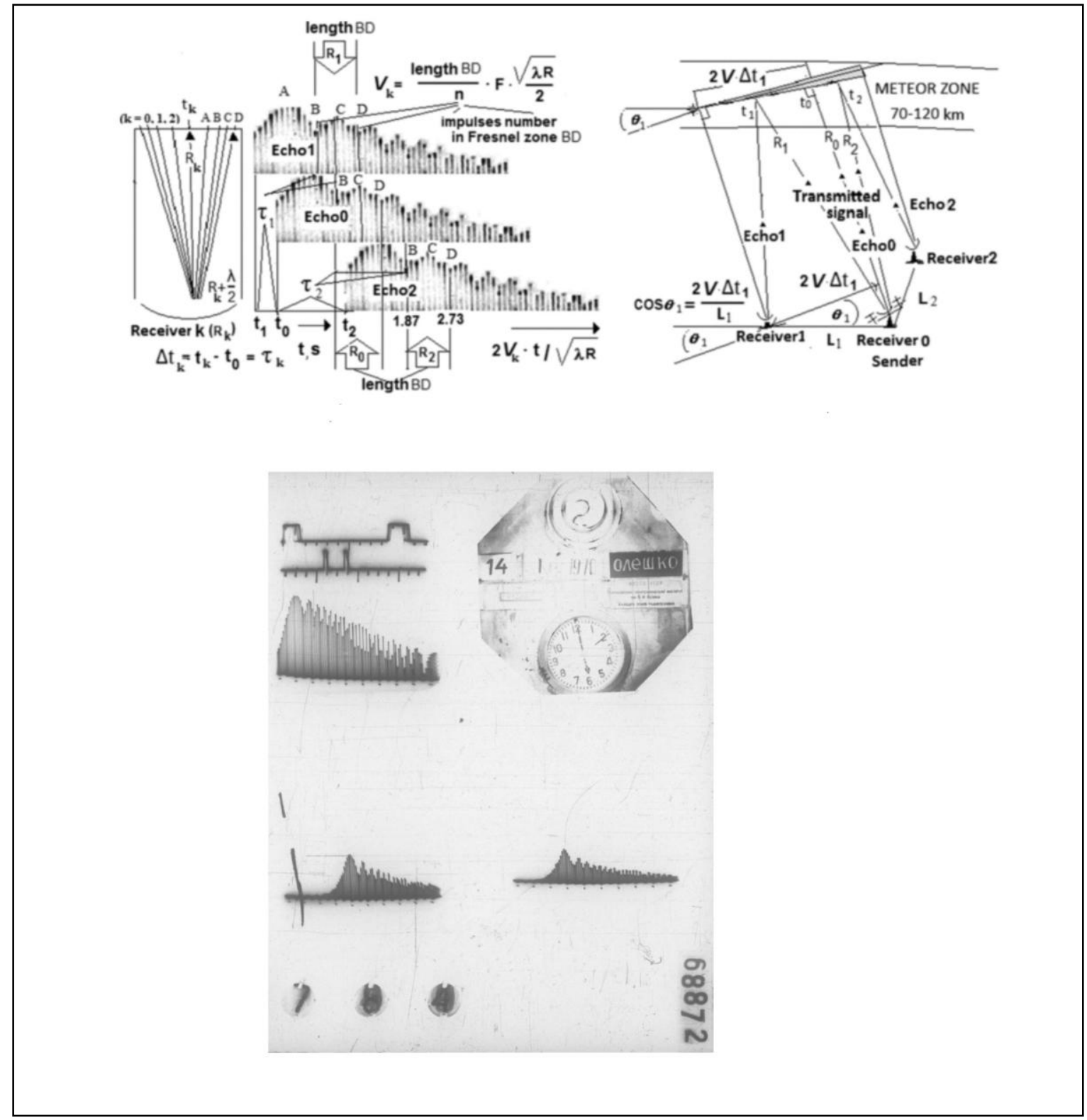

Fig. 2. Samples of entrance velocity and direction determination from old Kharkiv archives. The meteor can be seen in 3 photographs in the lower part of the figure, together with timing pulses, and the analysis of the images is shown in hand-drawn graphs above. Likely Fresnel zones are shown on the left, and trajectory determinations on the right [40]. These data are representative of results recorded in the period $1967-1970$; in this case the radar frequency was $22 \mathrm{MHz}[38,39]$ 
This $36.9 \mathrm{MHz}$ system had 2 sets of different tasks: the first was referred to as the "MS-1 complexes", and its purposes were (i) registration of the number of meteor reflections, (ii) recording the moment of the appearance of the meteor, (iii) recording the duration of the reflections, and (iv) measurement of the inclined range. The second set of tasks was denoted MS-2, and constituted determination of (i) the speed, (ii) the radiant and (iii) the orbits of meteor bodies, as well as some parameters concerning atmospheric movements at an altitude of $80-100 \mathrm{~km}$.

Both complexes used the same transmitter, but the receivers were different. In MS-1, the received radio meteor signals were recorded in the form of brightness marks on the screen of a cathode ray tube with a vertical range scan, and were recorded on a film with a continuous motion at a constant speed, in much the same way as already discussed at other sites e.g. [12]. MS-2 was, however, more complex. In addition to an amplitude channel, which was used to determine some parameters of the atmosphere, a phase channel was also arranged for determining the drift velocity of meteor traces in the atmosphere using a pulse-coherent Doppler frequency method. It was possible to input signals simultaneously from two receiving antennas, which made it possible to measure the angle of arrival of meteor signals using phase comparisons, and then to determine the height of the meteor at a known oblique range.

In both equipment complexes, the antennas were either "half-wave vibrator" or "wave channel" devices. Devices for protecting equipment from impulsive noise were also developed. Beginning in December 1958, the speed of meteoroids was determined by the pulse-diffraction method from the amplitude-time characteristics of a signal scattered on unsaturated meteor tracks [6], similarly to the Harvard system.

Radiants began to be registered in Kharkiv in December 1959 using the Davies pulsediffraction method [30]. The drift speed of meteor tracks in the Earth's atmosphere in Kharkiv began to be measured from March 1958 onwards. The Kharkiv equipment is mentioned here, since it was under the direction of Kashcheyev (and with his direct participation) meteor observations were carried out under the IGY 1957 program, which were recognized as one of the most successful among all participants in the Soviet Union and even on the world stage.

Fig. 2 shows sample photographic data from the Kharkiv radar. Images are shown there for the 3 sites used in the lower part of the figure, and interpretations are shown by sketches at the top. Like the Harvard radar, initial analyses required some degree of human interpretation. The outlier receiver antennas were located at a distance of $\sim 4.5 \mathrm{~km}$ and $\sim 7.0 \mathrm{~km}$ from the base station in 1959. The coherence condition was extended to the relay equipment (to study the effect of irregular winds on the accuracy of determining radians). For this, an additional ultrashort-wave communication line is used, through which a reference signal stabilized by quartz at a frequency $\mathrm{f}$ reference $=2 \mathrm{MHz}$ is transmitted from the main point to the remote stations. The VHF transmitter worked with amplitude modulation. With the Harvard system, signals were sent back to the base station via direct links (in this case cable rather than microwave, it appears).

The receiving devices consisted of four superheterodyne-type pulsed radio receivers. The receiver of the base station had one amplitude channel with a bandwidth of $45 \mathrm{kHz}$. The outlier stations often had more sensitive receivers (sometimes with adaptable gain levels), and the signals were sent from them to the main base station where they were further amplified and analysed.

In Kharkiv, an audit was carried out of the consistency of the US Harvard project, according to which sophisticated equipment was created at a wavelength of $7.3 \mathrm{~m}$ to study small meteor particles of mass $10^{-7}$ to $10^{-6} \mathrm{~g}$ [33]. Additionally, studies were carried out to determine which frequencies would be most reliable for meteor studies. It was concluded that the optimum frequencies were in the spectral band of 25 to $30 \mathrm{MHz}$. In particular, it was shown that the influence of the initial radius on the detectability of fast meteors is quite large. In the case of a high-power radar system operating at a frequency of $7.3 \mathrm{~m}$ (as in the US Harvard project discussed above), it is practically impossible to take into account the influence of the initial radius. Therefore it was felt that the published results of the US Harvard project are highly distorted, since speeds of more than $50 \mathrm{~km} \mathrm{~s}^{-1}$ were not recorded, yet many shower meteors do have higher speeds. For example, the Leonids have speeds of 
$71 \mathrm{~km} \mathrm{~s}^{-1}$, and the Perseids have speeds of $59 \mathrm{~km} \mathrm{~s}^{-1}$; the Kharkiv researchers concluded that the inability of the Harvard radar to measure the speeds of such meteors was due to the relatively high frequency of $40.92 \mathrm{MHz}$ used by the Harvard system.

The Kharkiv system was kept in operation much longer in its original form than the Harvard system. In 1968 - 1972, many of the detection processes at Kharkiv were automated, using digital processing, resulting in much faster system detection and identification. This was called MARS (Meteor Automated Radar System) [38, 39] and was able to determine and print 36 parameters of one meteor orbit in 5 seconds since 1972. In addition, using 6 different sensitivity levels every 5 minutes, the printing terminal displayed statistical data on the number of meteors: the number, distribution of amplitudes of the reflected signals and the parameters of this distribution, as well as the distribution of masses of recorded meteoroids with an indication of the confidence interval. It used a frequency of $31.1 \mathrm{MHz}$ since 1972, and could detect meteors down to the 12th magnitude in determining the orbits. In a 7-year period from 1972 to 1978 a total number of orbits of the order of 250,000 was achieved. The system not only measured meteor parameters for astronomical tasks - it also included comprehensive geophysical surveys, including measurement of atmospheric winds and other related parameters.

Experimental and theoretical meteor radar studies of Kharkiv scientists under the direction of Kashcheyev 1954 - the mid-1970's were reflected in numerous publications, e.g. [32 - 40], among which we note the report of Kashcheyev at a meeting of the special committee for conducting IGY 1957 in Moscow at the Xth GA IAU, as well as the monographs [31, 36].The monographs examined the physical theory of meteors, methods for recording meteor tracks during radio observations, issues of scattering of radio waves on ionized meteor tracks, experiment and results of measuring the number of meteors, equipment, methods and results of determining velocities and radiant individual meteors, methods, equipment, and results of studies of atmospheric circulation using the radio meteor method. The monograph [36] became, along with the monograph [31], a reference book and the leadership of more than one generation of meteor researchers and not only in the Soviet Union, but also abroad. The successes of research activities in the field of meteor radar in Kharkiv, led by Kashcheyev for the period 1954 - mid-70s, were demonstrated at the All-Union Symposium "Problems of Radio Meteor Research of the Atmosphere", October 4-6, 1977, which took place at the Kharkiv Institute of Radio Electronics (KHIRE), where all units headed by Kashcheyev related to meteor radar were transferred in 1971 (from KhPI).

In the photo (Fig. 3) some leaders of the USSR meteor research were captured. Several of these personnel have been mentioned in the text, especially Fedynsky and Kashcheyev. Fedynsky is the scientist who organized much of the radar method research implemented in the USSR. The photo was taken during the All-Union Radio Meteor Symposium-1977 near the KHIRE building, from left to right: Babadzhanov P.B. (Dushanbe), Fedynsky V. V. (Moscow), Kostylev V. K. (Kazan), Kashcheyev. B. L. (KHIRE, Kharkiv, Ukraine), Bronsten V. A.

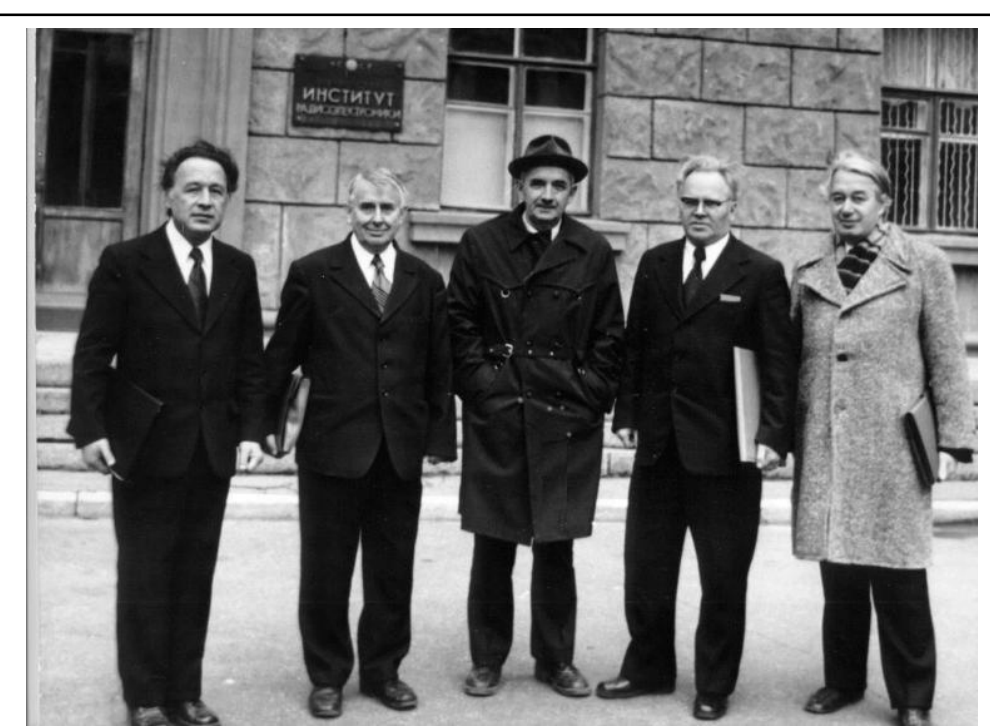

Fig. 3. Some leaders of the USSR meteor research in 1977 (Moscow). 


\section{Forward Scatter}

As noted above, forward scattering of radio waves has always been an area of pragmatic interest, since it can be used for communication. Small packets of information can be transmitted while a meteor trail lasts, then an electronic system can wait for another meteor trail to form and send subsequent messages, so that information may be sent in multiple short bursts - while possibly slow on average, it could be useful in cases in which an ionosphere, and communication satellites, do not exist. An example of some early studies in this regard can be found in [41]. A larger set of references can be found in [42].

This area of research has recently received new impetus as multi-static radars are becoming more common for wind studies - we will not discuss these further at this time.

\section{Mesospheric and Ionospheric Winds with Meteor Radar}

Above, we noted that in the earliest days, often two radars were used to measure all the meteor parameters. One was CW (to get phase) and one was pulsed (to get range). This was suitable for meteors, since in the main there is only one detected at a time, so it could be assumed that the received CW signal and the pulsed signal were from the same meteor. As radars became more powerful and more sensitive, the chance of 2 meteors being detected in the same beam at the same time increased, complicating matters. This could be resolved with later systems that combined pulsed and $\mathrm{CW}$ capabilities, as well as digitizing procedures, since items digitized at different ranges but at the same time could still be discriminated with such systems. But these capabilities took time to be incorporated.

One area which has not been discussed in sufficient detail to date was the area of wind measurement. Wind measurements could be made provided both pulsed and CW information were available (e.g. [27]). Collecting multiple radial drift velocities together in bins of typically an hour allowed the combined information to be used to deduce horizontal winds. Typically one might need 5-10 meteors at each height, and using $2 \mathrm{~km}$ height bins from 80 to $100 \mathrm{~km}$ altitude means 10 altitude bins, so that a count rate of 50 to 100 meteors per hour would be needed to determine a complete wind field. Less meteor detections were needed if the height-bins were larger. With some simpler systems, no height discrimination was possible, and the best that could be done was to generate hourly mean winds for the entire meteor height region $(80-100 \mathrm{~km})$. Such information, although less useful than height-dependent winds, was still of value.

So-called "meteor winds" became a mainstay of upper atmospheric/ionospheric research into dynamical processes in the 1960's and 1970's. Such research was undertaken at multiple sites all over the "Western" global arena as well as in the USSR. In regard to measurement of orbits, as discussed above, only a few radars are really needed world-wide to ensure coverage of the whole Earth, but in regard to winds, the situation is quite different. Each observing site has its own "weather", and every site is different. Even sites only a few hundred km apart can report different results. As a result, many sites sprung up to measure winds, from Britain to America to Canada to South America to Africa to Australia - and, of course, in the USSR. Optimum information could be achieved only by comparing data from many different sites, to enable better understanding of dynamical phenomena like tides, planetary waves, and mean flow circulations.

It was through extensive collaborations like this that the divide between East and West was softened, so that studies of atmospheric dynamics offered not only a means of scientific camaraderie but also kept the lines of communication between East and West alive. It is impossible to summarize the many papers in this field, but we can list a few. Of particlar note is the paper by Roper and Salah [43], which is representative of the type of multi-country co-operation which was involved in these type of studies. R.G. Roper was a prominent figure in this type of work: through his membership and leadership of committees like the Global Radio Meteor Wind Studies Project (GRMWSP), a sub-committee developed as a joint URSI/IAGA (Union of Radio Science International/International Association of Geomagnetism and Aeronomy) initiative, and IAMAP (International Association of Meteorology and Atmospheric Physics), he worked tirelessly to keep alive the 
ties between the USSR and the rest of the world. Other similar examples include [44, 45] - while they does not refer to the pre-1970 period, they embody all of the cooperation that was normal in such projects. Data in these projects were produced by a variety of equipment, including meteor radars with no height discrimination, and others which were able to separate out winds at different heights. Further examples from Kharkiv include [53, 54].

\section{Digitization and Data Storage}

At this stage, it is prudent to consider a factor which is not specifically related to meteors - that of data-acquisition and storage. Although to some extent this belongs in the section on the period from the mid-1970's to the 1990's (presented later), it also fits very well here.

A major breakthrough for all forms of atmospheric and meteor research was the so-called "digitizer" and the associated A/D (analog to digital converter). The following quote is from "https://spectrum-instrumentation.com/en/product-note-introduction-modular-waveform-igitizers":

"A digitizer is an electronic acquisition device that acquires analog waveforms, processes them through analog-to-digital converters (ADC's) and sends the digitized sample to a buffer, which allows them to be saved before being processed by a computer. Historically, modern digitizers date from the 1950's and 60's when the need to rapidly acquire, store, and process multiple channels of data became evident. Most early digitizers were built on NIM (Nuclear Instrumentation Module) or CAMAC (Computer Automated Measurement And Control ) interface standards. These are standard bus and modular crate electronics standards for data acquisition and control used in nuclear and particle physics experiments. The creation of a standard instrument interface bus (GPIB/IEEE 488 ) in the 1970's laid the foundation for multi instrument test and measurement systems. Concurrently the development of personal computers led to a number of standard computer interfaces such as PCI (Peripheral Component Interconnect) and VMEbus (VersaModular Eurocard bus) providing a standard interface to interconnect peripheral devices within a computer."

The advent of personal computers, plus the somewhat simultaneous development of digitizers in the early 1970's, was a major breakthrough for many areas of scientific research, and Meteor studies was no exception.

Phase coherent signals could be recorded at steps of a few tens of microseconds, allowing data to be recorded at range-steps of a kilometre or so. No longer was photographic recording needed, and nor was it necessary to employ staff to tediously read the photographs. Computer software could be used to analyze the (relatively) huge amounts of data now available. While useful for orbit calculations, digitization provided wind measurements with a huge boost in capabilities.

Originally data were stored on paper tape, or even computer cards, but as time passed, storage on magnetic tape became more common. Paper tape lasted longer; over a period of 20-30 years, magnetic tapes lose their information. Paper tape could be written and read at rates as high as 2000 characters per second, but magnetic tapes could record data even more quickly, and was much more efficient storage-wise. A $800 \mathrm{~m}$ spool of 9-track magnetic tape on a 10.5 " spool could store $200 \mathrm{MB}$ of data, which at the time was a lot of data.

These 2 types of data storage were prevalent right up to the 1980's and even into the 1990's.

\section{Meteor Radars after Digitization}

Another positive advance resulting from the availability of digitizers and personal/mini computers was the revision of way in which data were recorded. In the past, signal amplitude and phase were treated differently, but in the early 1970's, a new strategy was adopted. So-called "In-phase" and "Quadrature" signals were recorded, which in essence meant that two sets of amplitudes of the form $A \cos (\square t+\square)$ and $A \sin (\square t+\square)$ were produced [14], and these were digitized onto separate channels. These were extremely amenable to analysis, because the two components could be treated as real and imaginary components in a complex Fourier transform, making determination of spectra fast and easy. Subsequent determination of radial velocities and velocity variances was then also easy. 
Radars that adopted this new strategy profited enormously - those that did not adapt were left behind.

\section{The Spaced Antenna (D1) method}

Meteor studies of winds began to decline in importance after the mid-1970's - but not because of the reasons outlined by [2]. Rather, a new competitor arrive on the scene. A method referred to variously as the "Spaced Antenna Method", or the D1 method [46 - 48] became predominant in lower ionospheric work. It had various advantages over meteor methods: it had been nicely programmed to work with modern digitizers, it covered all of the meteor region $(80-100 \mathrm{~km})$ throughout day and night, and it also could measure down to 70 and even $60 \mathrm{~km}$ altitude - well below the meteor-zone. It also provided better temporal resolution than the hourly data provided by meteor winds. Comparisons between rocket, spaced antenna and meteor techniques showed generally good agreement [49-51]. In the period from 1975 and into the 1990's, the D1 technique became the premier method for mesospheric wind measurements, and meteor methods were considered a secondary technique.

However, this was not the end. One nagging feature about the D1 method was that it seemed to deteriorate above $90 \mathrm{~km}$ altitude. It turned out the reasons were not trivial - [52] was able to explain the reasons in terms of interference from the overlying E-region echoes. This, coupled with new meteor methods which increased meteor count rates by over 5 times, led to a resurgence of meteor methods in the 1990's. The claim by [2] that Meteor Science was dead was in error - it was simply taking a break! But that is another story, to be discussed in part 2 of this series.

\section{Conclusions}

A summary of radar meteor physics from the earliest days till the mid 1970's has been presented. Specific designs of different radars in various countries have been presented, and comparisons have been made. In a following paper, the years from 1975 to 2020 will be also summarized, and compared to these earlier days.

Acknowledgements. Important discussions with Peter G. Brown, Werner Singer and Sergei Kalabanov in preparation of this paper are gratefully acknowledged.

\section{References:}

1. Schafer J. P. and Goodall W.M.,Observations of Kennelly-Heaviside Layer Heights during the Leonid Meteor Shower of November 1931 // 1932, Proc. Inst. Radio Engrs, Vol. 20. P. 1941-1945.

2. Gilbert G.N., Growth and decline of a scientific speacialty: The case of Radar Meteor Research // 1977, Eos, Transactions American Geophysical Union, Vol. 58. P. 273-277.

3. Jarrell R.A. Canadian Meteor Science: The First Phase, 1933-1990 // 2009, Journal of Astronomical History and Heritage, Vol. 12(3). P. 224-234.

4. Kalabanov S.A., Karpov A.V., Sulimov A.I., et al., Progress of Radar Observations of Meteors in Kazan (Russia) over the Last Sixty Years // 2018, Proc. International Astronom. Union 13. P. 260--267 DOI: https://doi.org/10.1017/S1743921319000401

5. Millman P.M., McKinley D.W.R. and Burland Miriam S., Combined radar, photographic and visual observations of the Perseid meteor shower of 1947 // 1948, Nature, Vol. 161. P. 278-280.

6. Ellyett, C.D. and Davies J.G., Velocity of meteors measured by diffraction of radio waves from trails during formation // 1948, Nature, Vol. 161. P. 596-597.

7. Manning L.A, Villard O.G., Jnr. and A.M. Peterson, Double-Doppler Study of Meteoric Echoes // 1952, Journal of Geophys. Res., Vol. 57. P. 387-403.

8. McKinley D.W.R., Meteor velocities determined by radio observations // 1951, Astrophysical Journal, Vol. 113. P. 225-267.

9. Manning L.A., The theory of the radio detection of meteors // 1948, J.Applied Phys., Vol. 19. P. 689-699.

10. Manning L.A., Villmard O.G. and Peterson A.M., Meteoric echo study of upper atmosphere winds // 1950, Proc. IRE 38. P. 877-883.

11. Barratt P. and Browne I. C., A new method of measuring vertical currents // 1953, Q. J. R. Meteorol. Soc., Vol. 79. P. 550.

12. Robertson D. S., Liddy D.T., and Elford W.G., Measurements of winds in the upper atmosphere by means of drifting meteor trails I // 1953, J. Atmos. Terr. Phys., Vol. 4. P. 255-270. 
13. Elford W.G., A study of winds between 80 and $100 \mathrm{~km}$ in medium latitudes // 1959, Planet. Space Sci. P. 94101 .

14. Hocking W.K., Röttger J., Palmer R.D., Sato T. and Chilson P.B., Atmospheric Radar: Application and Science of MST Radars in the Earth's Mesosphere, Stratosphere, Troposphere, and weakly ionized regions // 2016, Cambridge University Press, ISBN 9781316556115, DOI: https://doi.org/10.1017/9781316556115,

15. Roper R.G. and Elford W.G., The seasonal variation of turbulence in the upper atmosphere // 1963, Nature, Vol. 197. P. 963-965.

16. Roper R. G., Atmospheric turbulence in the meteor region // 1966, J. Geophys. Res. Vol. 71. P. 5785-5792.

17. Jones J. and Morton J.D., The Determination of Meteor Shower Radiants from Single Station Observations // 1977, Bull. Astron. Inst. Czech., Vol. 28, No. 5. P. 267-272.

18. Lovell A.C.B., Meteor astronomy // 1954, Oxford (Clarendon Press). P. 463.

19. Millman P.M., The Springhill Meteor Observatory // 1957, National Research Council of Canada, REED Bulletin, Vol. 7. P. 4.

20. Kolomiyets S.V. and Sidorov V.S., IHY: Meteor astronomy and the New Independent States (NIS) of the Former Soviet Union // 2006, Proc. International Astronomic. Union. P. 189-198, DOI: 10.1017/S1743921307006989.

21. Kostylev K.V., Pupyshev Yu.A. and Sidorov V.V., Special equipment of the Engelgardt's Astronomical Observatory for radar observation of meteors // 1960, Bulletin of the Engelgardt's Astronomical Observatory, V. 35. P. 1-18. (in Russian)

22. Sidorov V.V. and Kalabanov S.A., A Method for Determining the Coordinates of Meteor Shower Radiants from Meteor Radar Goniometric Data // 2003, Solar System Research, Vol. 37, No. 2. P. 145-155 (Translated from Astronomicheskii Vestnik // 2003. Vol. 37, No. 2. P. 162-173).

23. Hawkins G.S. The Harvard radio meteor project // 1963, Smithsonian Contributions to Astrophysics, Vol. 7. P. 53-62.

24. Gill J.C. and Davies J.G., A radio echo method of meteor orbit determination // 1956, Monthly Notices Roy. Astron. Soc., Vol. 116. P. 105-113.

25. Weiss A. A. and Elford W.G., An equipment for the combined geophysical and astronomical measurements of meteors // 1963, Proc. Inst. Radio. Eng. Australia, Vol. 24. P. 197-293.

26. Nilsson C.S., A southern hemisphere radio survey of meteor streams // 1964, Australian J. of Physics, Vol. 17. P. 205-256.

27. Gartrell G. and Elford W.G., Southern Hemisphere Meteor Stream Determinations // 1975, Aust. J. Physics, Vol. 28. P. 591-620.

28. Lowenthal M., Meteor echoes from underdense trails at very high frequencies // 1956, Techn. report 132, Mass. Inst. Technol. Lincoln Laboratory.

29. Davies J.G. and Ellyett C.D., The diffraction of radio waves from meteor trails and the measurement of meteor velocities //1949, Phil. Mag., ser. 7(40). P. 614-626.

30. Davies J. G. J. and Gill J. C., Radio echo measurements of the orbits of faint sporadic meteors // 1960, Mon. Not. R. Astron. Soc., 121. P. 437-462.

31. McKinley D., Methods of Meteor Astronomy // 1964, Moscow: World. P. 383 (In Russian).

32. Kashcheyev B.L. and Kostylyov K.V., Meteor Rates Observed by Radio-Echo Techniques During the IGY-

IGC Period // 1963, Washington, D.C., Vol. 7. P. 63-65.

33. Kashcheyev B.L. and Lebedinets V.N. The Initial Radius of Ionized Meteor Trails // 1963, Washington, D.C., Vol. 7. P. 19-22.

34. Kashcheyev B.L., Lebedinets V.N. and Lagutin M.F., The Orbits of Meteor Streams Determined by RadioEcho Techniques // 1963, Washington, D.C., Vol. 7. P. 67-69.

35. Kashcheyev B.L., Radar observations of meteors according to the program of the International Geophysical Year // 1960, Research of the ionosphere and meteors. Digest of articles. Section V of the IGY program (Ionosphere and Meteors) Moscow: Publishing House of the USSR Academy of Sciences, No. 2. P. 40-53.

36. Kashcheyev B. L., Lebedinets V.N. and Lagutin M.F., Meteor phenomena in the Earth's atmosphere // 1967, Moscow : Nauka. P. 260. (In Russian).

37. Kashcheev B.L., Lebedinets V.N., Radar research of meteor phenomena // 1961, Moscow: Publishing House of the Academy of Sciences of the USSR, No. 7. P. 123.

38. Kashcheyev B.L., Delov I.A., Dudnik B.S., Tkachuk A.A., Radar complex for the study of weak radio meteors // 1971, Radio Engineering, Issue 16, KhSU Publishing House, Kharkiv. P. 11-18. (In Russian).

39. Kashcheyev B.L., Voloshchuk Yu.I., Tkachuk O.O. et al., Meteor automated radar system // 1977, Meteor Investigations. No.4, Moscow. P. 11-61. (In Russian).

40. Kolomiyets S.V., Uncertainties in MARS Meteor Orbit Radar Data Journal of Atmospheric and SolarTerrestrial Physics // 2015, Vol. 124, P.21-29 https://doi.org/10.1016/j.jastp.2015.01.007.

41. Forsyth P.A. and Vogan E.L., Forward-scattering of Radio Waves by Meteor Trails // 1955, Can. J. Physics., 33. P. 176-188.

42. Jones J. and Jones W., Oblique-scatter of radio waves from meteor trains: Full-wave calculations // 1991, Planetary \& Space Sci., 39(9). P. 1289-1296. 
43. Roper R.G. and Salah J.E., Preliminary results from the URSI/IAGA cooperative tidal observations program (CTOP) // 1978, J. Atmos. Terr. Phys., 40 (8). P. 879-885, https://doi.org/10.1016/0021-9169(78)90137-X.

44. Singer W., Hoffmann P., Manson A.H., et al., The wind regime of the mesosphere and lower thermosphere during the DYANA campaign-I Prevailing winds // 1994, J. Atmos.Terr. Physics., 56(13-14). P. 1717-1729.

45. Pancheva D., Merzlyakov E., Mitchell N.J., et al., Global-scale tidal variability during the PSMOS campaign of June-August 1999: interaction with planetary waves // 2002, J. Atmos. Solar-Terr. Phys., 64. P. $1865-1896$.

46. Mitra S. N., A radio method of measuring winds in the ionosphere // 1949, Proc. Instn. Electr. Engers. 96, III. P. 441-447.

47. Briggs B. H., Phillips G. J. and Shinn D.H., The analysis of observations on spaced receivers of the fading of radio signals // 1950, Proc. Phys. Soc., 63B. P. 106-121.

48. Briggs B.H., The analysis of spaced sensor records by correlation techniques // 1984, Handbook for MAP, Ground based techniques, 13. P. 166-186.

49. Lysenko I.A., Portnyagin, Yu.I., Sprenger, K., Greisiger, K.M. Schminder, R., Results of a comparison between radar meteor wind measurements and simultaneous lower ionosphere drift measurements in the same area // 1972, J. Atmosph. Terr. Phys. 34. P. 1435-1444.

50. Stubbs T.J., The measurement of winds in the D region of the ionosphere by the use of partially reflected radiowaves // 1973, J. Atmosph. Terr. Phys., 35. P. 909-919.

51. Vincent R. A., Stubbs T. J., Pearson P. H. O., Lloyd K. H. and Low C. H., A comparison of partial reflection drifts with winds determined by rocket techniques, 1 // 1977, J. Atmos. Terr. Phys., 39. P. 813-821.

52. Hocking W.K., Strengths and limitations for MST radar measurements of middle atmosphere winds //1997, Annales Geophys., 15. P. 1111-1122.

53. Kashcheyev B.L., Nechitailenko, V. A., Oleynikov, A.N., Peculiarities of the space-and-time structure of meteor winds // 1986, MAP Newsletter, No.3/4. P.7.

54. Kashcheyev B.L., Atmosphere dynamics in the equatorial meteor zone // 1987, Handbook for MAP., Urbana, Vol.25, August. P. 50-55, Published SCOSTEP.

University of Western Ontario, London, Ont., Canada;

Kharkiv National University of Radio Electronics

Received 25.01.2020 